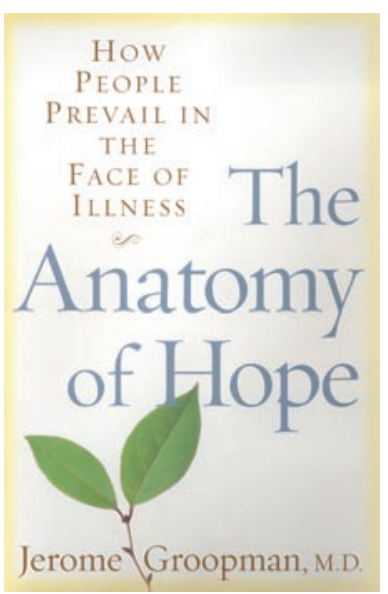

\section{The anatomy of hope}

How people prevail in the face of illness

\author{
Jerome Groopman \\ Random House, New York, New York, USA. 2004. \\ 272 pp. \$24.95. ISBN: 0-375-50638-1 (hardcover).
}

Reviewed by Nancy S. Green

E-mail:ngreen@marchofdimes.org n the foreword to his latest book, The Anatomy of Hope: How People Prevail in the Face of Illness, the oncologist-humanitarian Jerome Groopman lays open his thesis: "Hope, unlike optimism, is rooted in unalloyed reality... True hope has no room for delusion." He concludes his book with the bold statement that, "Hope, I have come to believe, is as vital to our lives as the very oxygen that we breathe."

Not all would agree that hope is a sturdy golden bough sustaining the ill or downtrodden. A contrasting perspective of hope as only a transient flicker is found in the Persian epic The Rubaiyat of Omar Khayyam, written in $1120 \mathrm{CE}$ : "The worldly hope men set their hearts upon / Turns ashes - or it prospers; and anon, / Like snow upon the desert's dusty face, / Lighting a little hour or two - is gone."

The divergent interpretations of hope's power likely stem from the dissimilarities in modern versus medieval sensibilities. Groopman's effort to synthesize his experiences into a wholesome verdict on humanity's strength is a fashionable response to pain and death that lies close to an optimistic extreme. In contrast to the Whitmanesque celebration of individual strength, Khayyam's perspective likely reflects the premodern wisdom of inescapable collective suffering. Can we ever turn fate's tide or even precisely predict the probability of disease survival?

Groopman is a smooth writer, what Jhumpa Lahiri might call the "interpreter of maladies," for the prestigious New Yorker magazine. His frequent contributions there bespeak his facility communicating with the public, as well as the lay thirst for insight into the depths of medical interactions. Groopman employs the successful recipe made popular by other physicianauthors, most notably Oliver Sacks, as he recounts the stories of several patient-physician interactions. As in Groopman's previous two books, this text is a synthesis of his own cheerful perspective on the woeful tales of desperate patients and the responses by their attending physicians, primarily Groopman himself.

The Anatomy of Hope attempts to provide insight into the power, or perceived power, of making choices for oneself, even choosing to avoid medical treatment, within the context of potential despair and grim medical consequences. There are gentle descriptions of rather familiar scenarios depicted in this anthology of clinical accounts: the young woman with advanced breast cancer who accepts doom as spiritual retribution, the oncologist who is harangued into his own radiation therapy with a happy regenerative outcome, the disillusioned daughter of a patient with advanced disease demanding more information, the senior pathologist who insists on an aggressive but seemingly futile treatment, only to end up cured, and the sensible, stoic dying woman.

Overall, Groopman superficially describes a faithful, even faith-based, approach to illness, while managing to skirt direct links to ecclesiastical benefits in survival. He and other popular medical authors attempt to interpret suffering in a larger context, with varying degrees of truths and truisms. The Anatomy of Hope is a collection of vignettes that will appeal most to the public, with descriptions of terminologies and issues typically understood by the medically initiated. This book may also serve the interests of medical trainees and wannabes, as much of Groopman's experience refers to his youthful oncology days of sculpting his own approach to patient suffering.

Does this book provide insight into humanity's strength, or is it one physician's attempt to synthesize observed suffering into an orderly construct to help sustain him in an emotionally demanding profession? As an oncologist I was unconvinced of the former, so the latter seems more likely to be true. The book is written for a rapid read and will add to the other books already occupying this popular literary niche by the telling of well-wrought stories that provide glimpses of juxtaposed commonality and individuality.

Rather than celebrating the healing power of hope, some patients successfully manage disaster simply by repressing memories of pain and doom associated with the hellishness of malignancy, surgery, and chemotherapy. Indeed, forgetting can be a useful coping technique, often implied but never addressed by Groopman's narratives. Forgetting can involve active neurologic processes, raising the possibility of its future utility as a therapeutic modality. Inducing amnesia, a practice used in anesthesia, may prove to be as effective as Groopman's "hope" for providing sustenance.

Groopman may be at least partially correct in that the ability to regulate one's own treatment, and to some extent outcome, in the face of biologic destiny is a component of hope. As another approach, I would frame the lesson for those whose vocations involve alleviation of the suffering of others this way: we can provide relatively little - information, choices, and a steadfast shoulder. Perhaps these services are adequate contributions to support hope for those facing desperate circumstances, possibly providing satisfaction and maybe even the perception of improved prognosis. My own interpretations are more modest, as the responses to impending suffering and death are often varied and unpredictable. 